mis and produces a mycelium, which develops in the very mass of the fleshy tissue. Later there appear, in addition, fructiferous filaments, which bear about twenty-five spores each. The cells of the fruit, on passage of the parasite, are destroyed, and it is thus that the crevices are formed.

THE diffusion which takes place between two gases separated from each other by an absorbent film (e.g., a soap film) was studied a short time ago by Prof. Exner, of the Vienna Academy. He has recently extended his inquiry to the case of vapours from easily volatile liquids, using the same apparatus as for permanent gases. The experiments were made with sulphide of carbon, chloroform, sulphuric ether, benzine, alcohol, and oil of turpentine, and they show that the diffusion from such vapours follows the same laws as those of gases, i.e., that it depends both on the coefficient of absorption of the film and on the density of the gas being directly proportional to the former, and inversely proportional to the square root of the latter. Thus it appears that the greater or less distance of a gas from its liquefaction point has at least no influence on this kind of diffusion.

IT is reported that Herr Josef Albert, the eminent Munich photographer, has made the highly important invention of photographing the natural colours of objects by means of a combina. tion of the ordinary photographic process with a photographic printing press constructed by the same gentleman some time ago. The images are stated to be so perfect that not the least improvement with the brush is required, as the finest shades of colours are faithfully reproduced. The secret of the invention is said to be based on the separation of white light into yellow, blue, and red rays, and in the artificial application of the same colours in the printing press. The first negative is taken upon a plate which is chemically prepared in such a manner that it only receives the yellow tints or shades of the object; this is then passed through the printing press, the roller of which is impreg. nated with a yellow colouring matter. On the print only the yellow tints reappear more or less distinctly; the object is then again photographed, and this time a negative is prepared,which only receives the blue shades and tints; a second printing press has its roller impregnated with some blue colour, and the plate of course gives a print with only the blue tints reproduced. In the same manner a third print is obtained which only shows the red shades and tints. The fiual manipulation now consists in printing the three images upon the same plate, when the three colours intermingle and the natural colours and shades of the objects are obtained, We need baraly point out the enormous importance of this invention.

A PAMPHLET just pablished by the Director of the Paris National Library contains some interesting statistical data respecting one of the finest libraries in the world. It has been found that the library contains 86,774 volumes on catholic theology, 44,692 volumes on the science of languages, 289,402 volum $s$ on law, 68,483 volumes on medicine, 441,836 volumes on French history, and 155,672 volumas of poetry. The works on natural science are not yet catalogued. During 1876 the library received no less than 45,300 Firench additions and purchased 4,565 foreign books.

THE additions to the Zoological Society's Gardens during the past week include two Black-eared Marmosets (Hapale penicillata) from South America, presented by Miss Quain; a Black-backea Jackal (Canis mesomeles) from South Africa, presented by Capt. Fulton, s.s. Taymouth Castle; a Common Boa (Boa constrictor) from South America, presented by Miss Alice Leith ; a Brown Tree Kangaroo (Dendrolagus inustus) from New Guinea, a Slow Loris (Nycticebus tardigradus) from Malacca, a River Jack Viper (Vifera rhinoceros) from West Africa, purchased; a Green Monikey (Cercofitheus callitrichus) from West Africa, deposited.

\section{THE LIBERT'Y OF SCIENCE IN THE MODERN STATE}

II.

$I^{\mathrm{T}}$ is easy to say: "A cell consists of small particles, and these we call plastidules; plastidules, however, are composed of carbon, hydrogen, oxygen, and nitrogen, and are endowed with a special soul; this soul is the product or the sum of the forces which the chemical atoms possess." Indeet this is possible; I cannot judge of it exactly. This is one of those points which are yet unapproachable for me; I feel there like a navigator who gets upon a shallow, the extent of which he cannot guess. But yet I must say that before the properties of carbon, hydrogen, oxygen, and nitrogen are defined to me in such a manner that I can understand how, through their combination a soul results, I cannot admit that we are justified in intruducing the plastidule soul into the educational programme or to ask generally of every educated man that he should recognise it as a scientific truth to such a degree as to operate with it logically, and to base his conception of the universe upon it. This we may really not ask. On the contrary, I think that before we designate such theses as the expression of science, before we say this is modern science, we ought first of all to complete a whole series of lengthy investigations. We must therefore say to the schoolmasters, do not teach this. This, gentlemen, is the resignation which in my opinion, those ought to exercise who deem such a solution in itself to be the probable end of scientific investigation. We can certainly not differ on that point for a moment, that if this doctrine of the soul were really true it couls only be confirmed by a long series of scientific investigations.

There is a series of events in the field of the natural sciences, by which we can show, for how long certain problems are in suspense, before it is possible to find their true solution. If this solution is found at last, and found in a direction of which there was a presentiment perhaps centuries ago, it does not follow that during those times which were occupied only by speculation or presentiment the problem might have been taught as a scientific fact.

Prof. Klebs spoke of contaginm animatum the other day, i.e. the idea that in diseases the transmission takes place by means of living organisms, and that these organisms are the causes of contagious diseases. The doctrine of contasium animutum loses itself in the obscurity of the middle ages. We have had this name handed down to us by our forefathers, and it is very prominent in the sixteenth century. Certain works of that period exist, which put down contagium animatum as a scientific dogma with the same confidence, with the same kind of justication, as nowadays the plastidule soul is set up. Nevertheless the living causes of diseases could not be found for a long time. The sixteenth century could not find them, nor could the seventeenth and the eighteenth. In the nineteenth century we have begun to find some contagia animata bit by bit. Zoology and botany have both contributed to them: we have found animals and plants which represent contagia, and a special part of the knowledge of contagia has been absorbed into zoology and botany, quite in the sense of the theories of the sixteenth century. But you will already have seen from the address of Prof. Klebs that the end of proofs has not yet ended. However much we may be disposed to admit the general validity of the old doctrine, now that a series of new living contagia have been found, now that we know cattle disease and diphtheria to be diseases which are caused by special organisms, still we may not yet say that now $a l^{\prime}$ contagia or even all infectious diseases are caused by living organisms. After it has appeared that a doctrine, which was formulated already in the sixteenth century, and which has since obstinately emerged again and again in the ideas of men, has at last, since the second decade of the present century, obtained more and more positive proofs for its correctness, we might really think that no $N$ it was our duty to infer, in the sense of an inductive extension of our knowledge, that all contagia and miasmata are living organisms. Indeed, gentlemen, I will admit that this conception is an extremely probable one. Even those investigators, who have not yet gone so far as to regard the contagia and miasmata as living beings have yet always said that they resemble living beings very closely, that they have properties which we otherwise know in living beings only, that they propagate their kind, that they increase

I Address delivered at the Munich meeting of the German Association,

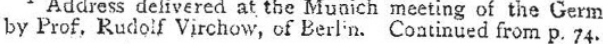


and are regenerated under special circumstances, that, indeed, they appear like real organic bodies,-these men, nevertheless, have waited, and rightly, until the proof of their being living organisms was furnished. And thus caution commands reserve even now.

We must not forget that the history of science presents a number of facts which teach us that very similar phenomena may happen in a very different manner. When fermentation was reduced to the presence of certain fungi, when it was known that its beginning was closely connected with the development of certain species of fungi, then it was really very obvious to imagine that all processes related to fermentation happen in the same way; mean all those processes which are comprised under the name of "catalytic," and which occur so frequently in the human and animal body as well as in plants. There were, indeed, some scientific men who imagined that digestion, which is one of the processes which closely resemble the fermentative ones, was brought about by certain fungi which occur frequently (in the special case of cattle the question has been practically discussed), and which were supposed to cause digestion in the stomach in the same way as the fermentation iungi canse fermentation elsewhere. We now know that the digestive juices have absolutely nothing to do with fungi. Much as they may posses. catalytic properties, we are yet certain that their active substances are chemical bodies which we can extract from them, which we can isolate from their other component parts, and which we can cause to act in the isolated state free from any admixture of living organisms. If the husaan saliva has the property of being able to change starch and extrine into sugar in the shortest time, and if every time we eat bread this new formation of "sweet" bread takes place in our mouth, then no' fungus iakes part in this nor any fermentation organism, but there are chemical substances which, mach in the same way as it happens in the interior of the fungus, bring about chemical change in matter. We see, therefore, that two processes which are extremely similar, the one in the interior of the fermentation fungus and the other in the process of human digestion, are brought about in different ways; the same process in the one instance is connected with a certain vegetable organism, while in the other it takes place without any such organism and simply through a liquid.

I should consider it a great misfortune if we were not to continue in the same way as I have done now, to examine in each single case whether the supposition which we make, the idea which we have formed and which may be highly probable, is really true, whether it is justified by facts. With regard to this I would remind you that there are cases also amongst the infectious diseases where most undoubtedly a similar contrast exists. My friend, Prof. Klebs, will no doubt pardon me if $I$, even now, in spite of the recent progress which the doctrine of infecting fungi has made, still remain in my reserve, and that I only admit that fungus which has been proved by demonstration, while $I$ deny all the other fungi as long as $I$ do not hear of fact; which attest them. Amon:st infectious diseases there is a certain group which are caused by organic poisons-I will only mention one of them, which, according to my opinion, is very instructive-I mean the poisoning by a snake-bite, a very celebrated and most remarkable form. If this kind of poisoning is compared with those kinds of poisoning which are generally called infectious diseases (infection does not signify much else than poisoning), then we must admit that in the courses both cases generally take the greatest analogies exist. With regard to the course of the illness nothing would oppose the supposition that the total sum of phenomena which occur in a human body after a snake-bite, were caused by fungi which entered the body and which produced certain changes in different organs. Indeed we know certain processes, septical ones, for instance, where phenomena of a completely similar nature occur, and it cannot be denied that certain forms of poisoaing by suake-bite resemble certain forms of septical infection as much as one egg resembles another. And yet we have not the least cause to suspect an importation of fungi into the body in the case of snake bite, while in the case of septic processes we, on the contrary, acknowledge and recognise this importation.

The history of our natural science has numerous examples, which ought always to cause us more and more to confine the validity of our doctrines in the most stringent manner to that domain only in which we can actually prove them, and that we do not by way of induction, proceed so far as to extend doctrines immeasurably which have only been proved for one or several cases. Nowhere the necessity of such a restriction has become more apparent than on the field of the theory of evolution. The question of the first origin of organic beings, this question which also forms the basis of progressive Darwinism, is an extremely old one. It is not known at all who first tried to find the different solutions for it. But if we remember the old popular doctrine, according to which all possible beings alive, animals and plants, could originate from a clod of clay-from a little clod urder circumstances--then we ought to remember at the same time that the celebrated coctrine of generatio conivoca, of epigenesis, is closely connected with it, and that it has been a common idea for thousands of years. Now with Darwinism the doctrine of spontaneous generation has been taken up again, ard I cannot deny that there is something very seductive in the idea of closing the theory of descent in this way, and, after the whole series of living forms has been constructed, from the lowest protozoa upwards to the highest human organism, to connect this long series with the inorganic world as well. This corresponds with that direction to generalise, which is so entirely human, that it has found a place in the speculation of man kind at all times, back wards to the most obscure periods. We have the undeniable desire not to separate the organic world from the universe, as a something which is divided from it, but rather to insure its connection with the universe. In this sense it is pacifying if one can say, the atom-group carbon and company -this is perhans speaking too collectively, but ye it is correct, since carbon is to be the essential element-therefore, this asso. ciation, carbon and company, has at some special time separated itself from the ordinary carbon and founded the first plastidule unter special circumstances, and continues to found it in the present. But in the face of this we must mention that alt real scientific knowledge of the phenomena of life has proceeded in an opposite direcion. We date the beginning of our real knowledge of the development of higher organisms from the day when Harvey pronounced the calebrated phrase, "Omne vivum ex ovo," every living being cumes from an egg. This phrase as we now know, is incorrect in its generality. To-day we can no longer recognise it as a fully jusifined one; we know that, on the contrary, a whole number of generations and propagations exist without ovi. From Harvey down to our celebrated firiend Prof. von Siebold, who obtained the general recognition of parthenogenesis, there lies a whole series of increasing restrictions, all of which prove that the phrase, "Omne vivum ex ovo" was incorrect speaking in a general sense. Nevertheless, it wotld be the highest ingratitude if we were not to acknowledge that in the opposition, which Y arvey assumed against the old gentratio cquivock, the greatest progress was made which has been made by science in this domain. Later on a great number of new forms were known, in which the propagation of the different kinds of living beings is going on, in which new individus is originate--direct separation, germation, metagenesis. All these forms, parthenogenesis included, are data which have caused us to give up every single (einheitliche) system for the generation of organic individuals. In place of a single scheme we now have a variety of data; we have no uniform system left by which we could explain once for all how a new animal being begins.

Generatio aquivoca, which has been disputed and refuted as many times, nevertheless faces us again and again. It is true that not a single positive fact is known which proves that generatio aquizoca has ever occurred, that spontaneous generation has ever taken place in such a way that inorganic masses, let us say the association carbon and company, have ever spontaneously developed into an organic substance. Nevertheless, I admit that if we indeed ruant to form an idea how the first organic being could have originated by itself, nothing remains but to go back to spontaneous generation. This is clear. If I do not want to suppose a creation.theory, if I do not want to believe that a. special creator existed, who took the clod of clay and blew his living breath into it, if $\mathrm{I}$ want to form some conception in $\mathrm{my}$ own way, then I must form it in the sense of generatio aquivoca. Tertium non datur. Nothing else remains if once we say "I do not admit creation, but I do want an explanation," If this is the first thesis, then we must proceed to the second and say "Ergo, I admit generatio equivoca." But we have no actual proof for it. Nobody has ever seen generatio aquivoca occurring in reality, and everyone who maintained that he had seen it, has been refuted, not by theologians indeed, but by naturalists. I mention this, gentlemen, in order to let our impartiality appear in the right light, and this is very necessary at times. We always have our weapons in ourselves and about us, to fight against that which is not justified.

I therefore say that I must admit the theoretical justification 
of such a formula. Whoever will have a formula, whoever says "I absolutely want a formula, I wish to be perfectly at one with myself, I must have a coherent conception of the universe," must either admit generatio aquivoca or creation; there is no other alternative. If we want to be outspoken we may indeed own that naturalists may have a slight predilection for genercatio aquivoca. It would be very beautiful if it could be proved.

But we must admit that it is not yet proved. Proofs are still wanting. If any kinc of proof were to be successfully given we would acquiesce. But even then it would have to be determined first, to what extent we could admit generatio equivoca. We should guietly have to continue our investigations, because nobody will think that spontaneous generation is valid for the totality of organic beings. Possibly it would only apply to a single series of beings. But I believe we have time to wait for the proof. Whoever remembers in what a regrettable manner, quite recently, all attempts, to find a certain basis for generatio cquivoca in the lowest forms of the transition from the inorganic to the organic world, have failed, should c nsider it doubly dangerous to demand that this ill-reputed doctrine should be adopted as a basis for all human conceptions of life. I may, doubtless, suppose that the story of the Bathybius has become known to nearly all educated persons. With this Bathybizus the hope has "gain vanished that generatio aquitroca can be proved.

I think, therefore, that with regard to this first point, the point of the connection between the organic and the inorganic, we must simply own that in reality we know nothing about it. We may not set down our supposition as a certainty, our problem as a dogma; that cannot be permitted. Just as in the progress of the doctrines of evolution it has been far more certain, more fertile, and more in accordance with the progress of accredited natural science, to analyse the original single doctrine part by part, we shall also have first to keep apart the organic and inorganic things in the old well-known analysing vay, and not to throw them together prematurely.

Nothing, gent:emen, has been more dangerous to natural science, nothing has done more harm to its progress and to its position in the opinion of nations than premature syntheses. While laying stress upon this, I vould point out specially how our Father Oken was damaged in the opinion not only of his contemporaries, but also in that of the following generation, because he was one of those who admitted syntheses into their conceptions to a far greater extent than a stricter method would have allowed. Do not let us lose the example of the natural philosophers; do not let us forget that every time that a doctrine which has assumed the air of a certain, well-founded, and reliable one, of one which claims general validity, tums out to be faulty in its outlines, or is found to be an arbitrary and despotic one in essential and great points, then a great number of men lose their faith in science entirely. Then the reproaches begin"You are not sure even yourselves; your doctrine, which is called truth to-day, is a falsehood to-morrow; how can you demand that your doctrine shill become the object of instruction and of the general consciousness?" From such experiences I take the warning that if we wish to continue to claim the attention of all we must resist the temptation of pushing our suppositions, our merely theoretical and speculative structures into prominence to such a degree that from them we would construct the concep. tion of the whole remaining universe.

\section{(To be continued.)}

\section{THE METEOR}

A METEOR of unusual brilliancy was seen on the evening of A Friday, the $23^{\text {rd }}$ inst., from various parts of the kingdom. Mr. I. A. Buxton writing to us from Hertford states that he saw it two miles north of that town at 8.26 P.M. He says :- "I was attracted ${ }^{2} \mathrm{y}$ its glare notwithstanding the moonlight, and saw it moving vertically downwards. I could not accurately observe its path, but it passed, nearly or exactly, over a small star, just visible in the moonlight, which $I$ think is $\pi$ Herculis, and disappeared suddenly before it reached the horizon, in about N.P.D. 60 and R.A. 16.40. By comparing notes with another observer (half a mile north of Hertford) it appears to have been visible much nearer the zenith than I had seen it; probably I saw the last $15^{\circ}$ of its path. From the apparent slowness of its motion and complete absence of sound I gather that it was far off. My guess at the moment was fifty miles. In consequence of its brightness its apparent diameter. was probably illusory. It attained two maxima of splendour, one about over the star named, the other at its disappearance. Scarcely any 'trail' was left ; what there was almost immediately vanished."

Mr. T. Mellard Reade writes that he saw it from Blundellsands, Liverpool, at 8.20 P.M. Looking up he saw a splendid broad streak of blue light terminating in a ball of red fire rushing across the sky in a north-westerly direction. The first flash seemed directly overhead; if so, Mr. Reade states, the meteor must have travelled through at least $45^{\circ}$. Shortly afterwards the moon being intensely bright and a shower coming on from the west, across the sea a most splendid "moon" rainbow made its appearance, finishing as a perfect arch of vivid colours with a second and a perfect bow above it.

Mr. W. B. Ferguson writes from Edinburgh that while walking down Princes Street about 8.25 P.M. he saw a most brilliant meteor which appeared to fall almost vertically and burst with great brilliance apparently just behind the castle. Its direction from where he observed it was $10^{\circ}$ west of south.

Mr. C. H. Dance, writing from Manor House, Ardwick, Manchester, gives the time as 3 h. $25 \mathrm{~m}$. P.M. Greenwich mean time. The meteor, he states, appeared to come from the constellation Cassiopeia, and after travelling in a direction a little to the west of north, finally burst behind a cloud about thirty degrees above the horizon. The apparent size of the meteor was considerably greater than that of Mars during the late opposition, and the light which it emitted was intensely bright and of a bluish-green colour, leaving a decidedly red impression on the retina. The period of visibility would be about five seconds, and the sparks in the train were also visible for some seconds.

Mr. Plant, the Curator of the Salford Museum, observed the meteor at the same time, visible to the north of Manchester.

Dr. S. Drew, of Sheffield, saw it at about 8.30 P. ir. He gives the apparent diameter as two minutes; path, from the square of Pegasus to near Altair ; motion, slow; shape, at first globular, aiterwards elongated, with tail. It then appeared to break up. Colour, at first blue-green, afterwards ruddy ; light, brilliant. He heard no sound accompanying the meteor, and from the absence of sound and slow apparerit motion, he infers the real distance and size of the bolide to have been great. Dr. Drew was, at the time of observation, a little to the west of the town of Rotherham.

Several correspondents write to the Times describing what they saw of this remarkable meteor, for it is evidently the same body which has been seen by the various observers. The Liver. pool correspondent of the Times saw it about $8 \cdot 30$. "A large ball of fire shot from the sky, exploding and throwing off innumerable variegated sparks as it descended in a northerly direction. The track of sparks gave the meteor the appearance of a brilliant comet with a long tail. Some spectators state that they heard the hissing noise made in its course, and others allege that it descended into the water near the bar of the Mersey with a great noise, sending up a column of steam and spray."

Mr. Donald Mackay saw it from Victoria Street, London, shortly before 8.30 P.M. "It travelled with great rapidity for about $20^{\circ}$ from the zenith to the horizon, bursting in a white ball as large as twelve of the planet Mars in one, lighting up all the houses surrounding Victoria Street, the point of observation, and leaving a large tail behind of the shape of a spear-head, with all the colours of the rainbow in it."

The Rev. J. Hoskyns-Abrahall writes from Combe Vicarage, near Woodstock, that about 8.20 the northern sky was suddenly lighted up with a glow that outshone that spread over the south-eastern sky by a moon nearly full. "Looking northwards I saw a globular meteor of a pale orange colour descending perpendicularly. Its apparent size was scarcely less than that of the moon. Just above the slope on which I was, and seemingly not half a mile off, it burst into huge fragments, which flared forth with a fierce, lightning-like, reddish glare, and scattered sparks of surpassing splendour."

Mr. D. Aldred writes from Milford, Derby, to the same effect. He saw the meteor about six miles north of Derby, about 8.25. "It was almost due north, and travelling from the zenith to the horizon, the point of dispersion being about $45^{\circ}$ above the north point of the horizon. In shape it was conical, the greatest breadth about one and a half times the diameter of the moon. It left a trail of considerable length, and the colours detached were of most remarkable brilliancy."

"R. M. C." writes from Cathedine, Brecknockshire, giving the report of two reliable witnesses who were walking in an easterly direction at 8.25 P.M. Looking back, the moon being at the time obscured by a cloud, they saw a ball of the most intense white light, "about the size of a cannon-ball," travers- 